\title{
PERENCANAAN PENGELOLAAN HUTAN RAKYAT DI TANA TORAJA
}

\author{
Management Planning of Public Forest in Tana Toraja Regency \\ Daud Malamassam
}

\begin{abstract}
A study on the management planning of Public Forest in Tana Toraja Regency was implemented with the aim of establishing a concept for forest product regulation in order to attain an optimum result and benefits in the interest of the owners and regional development. As the result, the public forest that located on 10 districts in Tana Toraja Regency can be organized into four Management Units. By an appropriate management treatments, every management unit can present an adequate and sustainable quantity of raw material for wood processing industries in this region.
\end{abstract}

Keywords: Management Planning, Public Forest, Yield Sustainability, Management Unit, and Annual Allowable Cut

\section{PENDAHULUAN}

Hutan Rakyat di Sulawesi Selatan, telah berperan secara nyata dalam pemenuhan berbagai kebutuhan kayu; mulai dari kayu bakar, bahan untuk kelengkapan sarana upacara-upacara keagamaan / adat, bahan bangunan. Produksi kayu dari hutan rakyat ini semakin menjadi andalan dalam upaya pemenuhan kebutuhan kayu masyarakat, sejalan dengan semakin menurunnya produksi kayu rimba dari hutan alam.

Khusus di Kabupaten Tana Toraja, terdapat areal hutan rakyat seluas $77.000 \mathrm{Ha}$ lebih, yang terdiri atas hutan bambu (murni dan campuran), kebun campuran dan hutan pinus murni (Dishut Kabupaten Tana Toraja, 2005). Pembangunan hutan bambu dan hutan kebun campuran telah dilakukan oleh masyarakat Tana Toraja jauh sebelum Program Penghijauan dicanangkan oleh Pemerintah, dan malahan keberadaannya tidak bisa dipisahkan dari sejarah keberadaan masyarakat Toraja. Hutan-hutan ini telah menjadi pemasok berbagai kebutuhan kayu setempat, termasuk untuk memenuhi kebutuhan pembangunan Rumah Adat, yang semula seluruh bahannya terdiri dari kayu dan bambu.

Menyangkut hutan pinus, yang merupakan hasil Program Penghijauan, pemanfaatannya secara intensif baru dilakukan selama beberapa tahun terakhir. Pemanfaatan secara intensif termaksud nampaknya didorong oleh :

1. Semakin terbatasnya bahan baku kayu dari hutan alam
2. Adanya kemajuan di bidang teknologi kayu yang dapat meningkatkan nilai ekonomi dan nilai guna dari kayu-kayu lunak, termasuk pinus.

Hal ini telah menyebabkan para pengelola indusri perkayuan melirik kayu-kayu dari hutan tanaman, termasuk tanaman pinus yang ada di Tana Toraja, untuk memenuhi kebutuhan bahan baku industri mereka, dan sekaligus membuka peluang pasar bagi para pemilik hutan rakyat yang bersangkutan. Dengan demikian, hutan pinus yang semula dipahami dan dinilai oleh warga masyarakat sebagai sesuatu yang tidak atau kurang memberikan manfaat ekonomi bagi pemiliknya, berubah menjadi sebuah asset atau sumber dana untuk memenuhi berbagai kebutuhan.

Perubahan nilai dan pemahaman termaksud di atas, jika tidak dikelola dengan baik, potensil akan menyebabkan ludesnya tanaman pinus dalam waktu yang tidak terlalu lama. Para pemilik dan juga pihak-pihak yang terkait dengan pemanfaatan tanaman pinus cenderung akan mengejar kepentingan jangka pendek dan cenderung tidak lagi mau memikirkan bahwa kondisi hutan tanaman pinus yang ada saat ini tercipta melalui proses ekologis selama puluhan tahun.

Dalam rangka menjamin pemanfaatan tanaman termaksud di atas secara optimum dan berkesinambungan bagi kepentingan para pemiliknya dan masyarakat Tana Toraja pada umumnya, maka diperlukan suatu perencanaan jangka panjang dan jangka menengah. Penelitian ini bertujuan untuk menyusun sutau konsep penataan dan pengaturan hasil tanaman pinus 
(hutan 'pinus' rakyat) di Kabupaten Tana Toraja yang dapat menjamin kelestarian hutan rakyat yang bersangkutan beserta kesinambungan manfaatnya, baik bagi para pemiliknya maupun bagi pembangunan perekonomian daerah / wilayah.

\section{METODE PELAKSANAAN}

\section{Jenis Data dan Metode Pengumpulannya}

Data yang dikumpulkan dalam kegiatan ini meliputi data primer dan data sekunder. Data primer antara lain meliputi data kerapatan dan potensi tanaman pinus per satuan luas, sedang data sekunder yang diperoleh melalui laporan-laporan atapun dokumen-dokumen yang relevan antara lain meliputi luas dan penyebaran tanaman di setiap bagian wilayah.

Pengumpulan data potensi tegakan dilakukan dengan menggunakan petak-petak ukur seluas 0,1 Ha yang dipilih secara purposif (Malamassam, 1998) dengan mengupayakan agar semua kondisi tanaman pada masing-masing bagian wilayah dapat terwakili. Jumlah petak ukur yang diamati pada masingmasing bagian wilayah (10 kecamatan) adalah minimal 30 buah (Tiro, 2000).

\section{Pengolahan Data}

Data potensi yang dikumpulkan dianalisis untuk menentukan etat tebangan yang dapat menjamin kelestarian hasil. Berhubung pengukuran luas tidak sempat dilakukan, maka perhitungan etat dilakukan dengan asumsi bahwa luas tanaman yang secara efektif berproduksi adalah $75 \%$ dari luas total tanaman. Diasumsikan pula bahwa jangka pengusahaan tanaman adalah 20 tahun, yang sekaligus digunakan sebagai daur tanaman untuk satu rotasi ke depan. Dengan demikian, Etat atau Annual Allowable Cut (Davis, 1982) ditetapkan dengan rumus :

$$
\begin{array}{ll}
\text { Etat Luas }\left(E_{L}\right)= & \text { Luas Efektif } / \text { daur } \\
\text { Etat Volume }\left(E_{V}\right)= & \text { Luas Efektif } x \text { Volume rata- } \\
& \text { rata per Ha } / \text { daur }
\end{array}
$$

\section{HASIL DAN PEMBAHASAN}

\section{Potensi Hutan Rakyat}

Hasil inventarisasi hutan rakyat berupa tanaman pinus adalah seperti yang tertera pada Tabel 1. Pada tabel ini dapat dilihat bahwa secara rata-rata potensi kayu dari tanaman pinus di sepuluh kecamatan, berkisar antara 168,3 166,1 $\mathrm{m}^{3}$ per Ha sampai $\mathrm{m}^{3}$ per $\mathrm{Ha}$, atau rata-rata sebesar $170,5 \mathrm{~m}^{3}$ per $\mathrm{Ha}$ untuk keseluruhan tanaman pinus yang ada di Kabupaten Tana Toraja. Selanjutnya dapat pula diketahui bahwa taksiran potensi total untuk keseluruhan tanaman pinus seluas 10.297,4 $\mathrm{Ha}$ yang ada pada 10 kecamatan mencapai $1.732 .829,8 \mathrm{~m}^{3}$ atau berkisar antara $1.710 .175,6 \mathrm{~m}^{3}$ sampai $1.755 .484,1 \mathrm{~m}^{3}$ pada taraf kepercayaan $95 \%$.

Jika kerapatan atau jumlah pohon normal diasumsikan sebanyak 400 pohon per Ha, maka tingkat kerapatan pohon pada hutan rakyat di Kabupaten Tana Toraja mencapai $67 \%$ sampai

\begin{tabular}{|c|c|c|c|c|c|c|c|c|}
\hline \multirow[t]{2}{*}{ No. } & \multirow[t]{2}{*}{ Kecamatan } & \multirow[t]{2}{*}{$\begin{array}{l}\text { Luas HR } \\
\text { Pinus (Ha) }\end{array}$} & \multirow{2}{*}{$\begin{array}{l}\text { V Rata- } \\
\text { rata } \\
\left(\mathrm{m}^{3} / \mathrm{Ha}\right)\end{array}$} & \multirow[t]{2}{*}{ SE } & \multicolumn{2}{|c|}{$\begin{array}{c}\text { Taksiran } \\
\text { Volume Rata- } \\
\text { rata (m³/Ha) }\end{array}$} & \multicolumn{2}{|c|}{$\begin{array}{c}\text { Taksiran Volume Total } \\
\left(\mathrm{m}^{3}\right)\end{array}$} \\
\hline & & & & & Min. & Maks. & Min. & Maks. \\
\hline 1. & Mengkendek & $2.702,6$ & 168,8 & 2,54 & 166,2 & 171,3 & $449.190,1$ & $462.919,0$ \\
\hline 2. & Sangalla & $1.595,0$ & 207,1 & 0,89 & 206,2 & 208,0 & $32.8 .842,5$ & $331.681,6$ \\
\hline 3. & Buntao' Rantebua & $1.216,0$ & 203,6 & 1,58 & 202,0 & 205,2 & $245.666,8$ & $249.509,4$ \\
\hline 4. & Tondon Nanggala & 142,6 & 148,5 & 0,99 & 147,5 & 149,5 & $21.022,4$ & $21.304,6$ \\
\hline 5. & Rantetayo & $1.617,5$ & 148,5 & 0,81 & 147,7 & 149,3 & $238.829,8$ & $241.450,2$ \\
\hline 6. & Saluputti & 321,8 & 133,5 & 1,03 & 132,5 & 134,6 & $42.634,2$ & $43.297,2$ \\
\hline 7. & Bittuang & 418,0 & 143,2 & 1,34 & 141,9 & 144,6 & $59.308,1$ & $60.428,4$ \\
\hline 8. & Rindingallo & $2.010,0$ & 146,5 & 1,03 & 145,5 & 147,5 & $292.350,1$ & $296.490,7$ \\
\hline 9. & Sa'dan Balusu & 169,0 & 147,8 & 0,85 & 147,0 & 148,7 & $24.841,7$ & $25.129,0$ \\
\hline 10. & Sesean & 105,0 & 146,5 & 1,07 & 145,4 & 147,6 & $15.267,8$ & $15.492,5$ \\
\hline & Nilayah Studi & $10.297,4$ & 168,3 & 2,20 & 166,1 & 170,5 & $1.710 .175,6$ & $1.755 .484,1$ \\
\hline
\end{tabular}
$85 \%$ dari tingkat kerapatan normal. Hutan rakyat di

Tabel 1. Potensi Hutan 'Pinus' Rakyat pada setiap Kecamatan Kabupaten Tana Toraja

Sumber : Hasil Analisis Data Tahun 2005 
Tabel 2. Jumlah pohon, diameter dan tinggi bebas cabang rata-rata pohon pada hutan rakyat di Kabupaten Tana Toraja

\begin{tabular}{|l|c|c|c|c|c|}
\hline \multirow{2}{*}{ Kecamatan } & Jumlah phn & \multicolumn{3}{|c|}{ Diameter $(\mathrm{cm})$} & \multirow{2}{*}{ Tinggi Bebas Cabang } \\
\cline { 3 - 4 } & per Ha & Min & Rata $^{2}$ & Maks & \multirow{2}{*}{ Rata $^{2}(\mathrm{~m})$} \\
\hline 1. Mengkedek & 301 & 10,8 & 30,7 & 70,0 & 10,0 \\
\hline 2. Sangalla & 285 & 18,0 & 38,6 & 78,0 & 9,3 \\
\hline 3. Buntao' Rantebua & 307 & 18,0 & 34,2 & 70,0 & 9,5 \\
\hline 4. Tondon Naggala & 315 & 18,0 & 28,8 & 48,0 & 12,0 \\
\hline 5. Rantetayo & 315 & 10,0 & 28,8 & 47,1 & 10,2 \\
\hline 6. Saluputti & 268 & 11,0 & 27,7 & 49,4 & 10,5 \\
\hline 7. Bittuang & 297 & 10,9 & 25,5 & 51,0 & 10,2 \\
\hline 8. Rindingallo & 324 & 10,5 & 26,1 & 49,0 & 11,3 \\
\hline 9. Sa'dan Balusu & 307 & 10,0 & 27,6 & 50,9 & 11,8 \\
\hline 10. Sesean & 340 & 12,0 & 22,4 & 42,0 & 11,3 \\
\hline Rata-rata & 306 & 12,2 & 29,0 & 55,5 & 10,6 \\
\hline
\end{tabular}

Sumber : Hasil Analisis Data Tahun 2005

Kecamatan-Kecamatan Sesean, Rindingallo, Rantetayo, Tondon Nanggala, Sa'dan Balusu, Buntao' Rantebua, dan Mengkendek memiliki tingkat kerapatan pohon antara $75 \%$ sampai $85 \%$. Sebaliknya, hutan rakyat pada KecamatanKecamatan Bittuang, Sangalla dan Saluputti, memiliki tingkat kerapatan pohon yang lebih rendah yaitu antara $65 \%$ sampai $74 \%$ dari kerapatan normal.

Tabel 2 juga memperlihatkan bahwa diameter rata-rata pohon berkisar antara $22 \mathrm{~cm}$ sampai $39 \mathrm{~cm}$. Diameter rata-rata yang terkecil di jumpai di Kecamatan Sesean, yang nampaknya berasosiasi dengan tingkat kerapatan pohon yang tinggi. Sebaliknya diameter rata-rata yang besar secara berturut-turut dijumpai di Kacamatan Sangalla, Buntao' Rantebua dan Mengkendek. Hal lain yang dapat disimak dari Tabel 2 ini adalah bahwa Kecamatan Tondon Nanggala dan Sa'dan Balusu cenderung memperlihatkan bonita atau kualitas tempat tumbuh yang lebih baik untuk pinus, sebagaimana diindikasikan oleh tinggi pohon pinus yang lebih besar pada kedua kecamatan ini bila dibanding dengan tinggi pohon pinus yang terdapat di kecamatan yang lain.

\section{Penataan Hutan}

Hasil inventarisasi menunjukkan bahwa tanaman pinus rakyat di Kabupaten Tana Toraja pada umumnya merupakan tegakan seumur dengan kelas umur yang hampir seragam (15 -25 tahun), meskipun di beberapa lokasi ditemukan adanya tanaman pinus yang masih tergolong muda yaitu sekitar lima tahun. Berdasarkan kondisi ini maka sistem pengelolaan yang dapat menjamin kelestarian hasil Hutan Rakyat Pinus di Kabupaten Tana Toraja, adalah sistem Tebang Pilih dengan Permudaan Buatan atau Sistem Tebang Jalur searah Kontur dengan Permudaan Buatan.

Potensi Hutan Rakyat Pinus yang menyebar padaa 10 kecamatan memerlukan penataan areal atas empat Satuan Pengelolaan Hutan Rakyat (SPHR), dengan rincian luas dan potensi seperti yang tertera pada Tabel 3. Keempat SPHR yang dimaksud masing-masing adalah sebagai berikut :

1. SPHR - I meliputi Kecamatan Mengekendek dan Sangalla

2. SPHR - II meliputi Kecamatan Buntao' Rantebua dan Tondon Nanggala

3. SPHR - III meliputi Kecamatan Rantetayo, Saluputti dan Bittuang

4. SPHR - IV meliputi Kecamatan Rindingallo, Sesean dan Sa'dan Balusu

5. SPHR - V meliputi Kecamatan Bonggakaradeng dan Simbuang

Dengan asumsi bahwa $75 \%$ dari total luas merupakan bagian yang efektif diusahakan untuk tujuan produksi, maka luas efektif hutan pinus pada keempat SPHR tersebut di atas adalah 7.723 ha. Jika jangka waktu pengusahaan hutan pinus 20 tahun maka luas etat tebangan per tahun adalah 386,2 Ha. Secara diagramatik penataan areal disajikan pada Gambar 1. Pada gambar ini diperlihatkan bahwa Satuan Pengelolaan Hutan Rakyat - I (SPHR - I) mempunyai etat luas tebangan tahunan yang terbesar yaitu 161,2 Ha per tahun, sedang SPHR-II mempunyai etat luas tebangan tahunan yang terkecil yaitu sebesar 50,9 Ha per tahun. 
Tabel 3. 'Rencana Satuan Pengelolaan Hutan Rakyat (SPHR) di Kabupaten Tana Toraja

\begin{tabular}{|c|c|c|c|c|}
\hline \multirow{2}{*}{ No. } & \multirow{2}{*}{ SPHR } & \multirow{2}{*}{ Kecamatan } & \multicolumn{2}{|c|}{ Taksiran Total Potensi } \\
\hline & & & (Ha) & $\left(m^{3}\right)$ \\
\hline \multirow{3}{*}{1.} & \multirow{2}{*}{ SPHR - I } & Mengekendek & $2.702,6$ & $456.055,3$ \\
\hline & & Sangalla & $1.595,0$ & $330.260,7$ \\
\hline & \multirow{4}{*}{ SPHR - II } & Sub Jumlah & $4.297,6$ & $786.316,0$ \\
\hline \multirow{4}{*}{2.} & & Buntao' Rantebua & $1.216,0$ & $247.589,8$ \\
\hline & & Tondon Naggala & 142,6 & $21.163,0$ \\
\hline & & Sub Jumlah & $1.358,6$ & $268.752,7$ \\
\hline & \multirow{3}{*}{ SPHR - III } & Rantetayo & $1.617,5$ & $42.966,7$ \\
\hline \multirow{4}{*}{3} & & Saluputti & 321,8 & $59.870,1$ \\
\hline & & Bittuang & 418,0 & $240.134,1$ \\
\hline & \multirow{5}{*}{ SPHR - IV } & Sub Jumlah & $2.357,3$ & $342.970,9$ \\
\hline & & Rindingallo & $2.010,0$ & $294.424,8$ \\
\hline \multirow[t]{4}{*}{4} & & Sesean & 105,0 & $24.985,0$ \\
\hline & & Sa'dan Balusu & 169,0 & $15.380,4$ \\
\hline & & Sub Jumlah & $2.284,0$ & $334.790,2$ \\
\hline & & & $10.297,4$ & $1.732 .829,8$ \\
\hline
\end{tabular}

Sumber : Dinas Kehutanan Kab.Tana Toraja dan Hasil Analisis Data, 2005

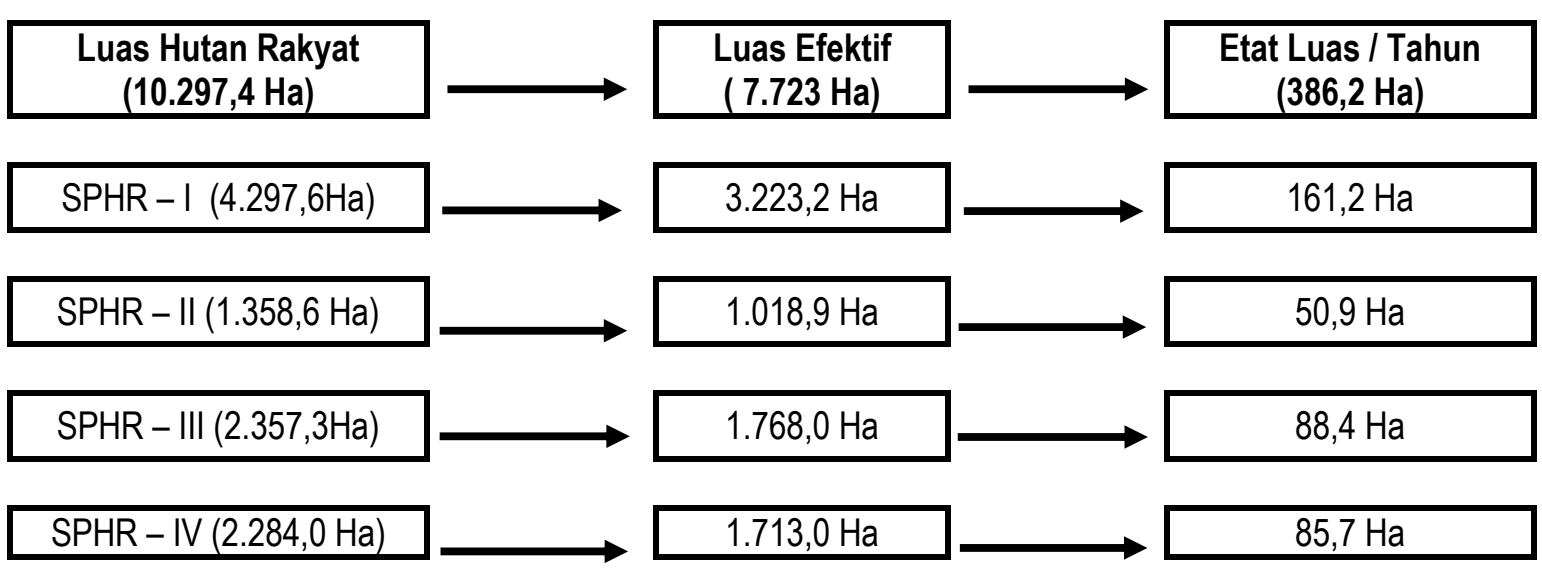

Gambar 1. Penataan Wilayah Hutan Rakyat

\section{Alokasi Penebangan dan Target Produksi}

Pada bagian terdahulu telah disebutkan bahwa berdasarkan kondisi hutannya maka pengelolaan hutan rakyat di Kabupaten Tana Toraja yang merupakan hutan pinus murni dilakukan dengan Sistem Tebang Pilih dengan Permudaan Buatan atau Sistem Tebang Jalur searah Kontur dengan permudaan Buatan, yang secara diagramatik tiperlihatkan pada Gambar 2.

Luas efektif areal yang akan dikelola dengan sistem ini adalah $7.723 \mathrm{Ha}$ yang tersebar pada 10 kecamatan. Berdasarkan kondisi ini maka dapat disajikan rata-rata Etat Luas dan Etat Volume tiap kecamatan pada Tabel 4. Dari Tabel 4 diketahui bahwa tanaman pinus di Kecamatan Mengkendek memiliki etat terbesar, yaitu sebanyak 17.102,1 $\mathrm{m}^{3}$ per tahun, kemudian secara berturut-turut dikuti oleh Kecamatan Sangalla (12.384,8 $\mathrm{m}^{3}$ per tahun) dan Kecamatan Rindingallo $\left(11.040,9 \mathrm{~m}^{3}\right.$ per tahun). Hutan pinus raakyat pada ketiga wilayah kecamatan ini, pada hakekatnya, dapat dikelola 
sebagai suatu Kelas Kelestarian tersendiri. Namun dalam rangka lebih menjamin efektifitas pengelolaan dan kestabilan produksi untuk jangka panjang, maka hutan pinus pada ketiga wilayah tersebut perlu dikelola secara bersama-sama sebagai suatu unit pengelolaan dengan hutan pinus rakyat yang terdapat di kecamatan lain.

Sekaitan dengan hal termaksud terakhir di atas, keseluruhan hutan pinus rakyat yang ada perlu dikelompokkan atas empat Satuan Pengelolaan (SPHR), yaitu SPHR I, II, III dan IV. Alokasi penebangan dan target produksi untuk setiap Satuan Pengelolaan Hutan Rakyat disajikan pada Tabel 5. Pada tabel tersebut dapat dilihat bahwa etat atau Jatah Tebang Tebangan untuk keempat SPHR adalah 386,2 Ha dengan produksi sebesar 64.981,1 $\mathrm{m}^{3}$ per tahun atau $5.415,1$ per bulan. Etat volume tertinggi terdapat di SPHR-I yaitu sebesar 29.486,9 $\mathrm{m}^{3}$ per tahun atau rata-rata sebesar $2.457,2 \mathrm{~m}^{3}$ per bulan dan terendah di SPHR-II yaitu sebesar $10.078,2 \mathrm{~m}^{3}$ per tahun atau rata-rata sebesar 839,9 $\mathrm{m}^{3}$ per bulan. Angka ini menunjukkan bahwa etat volume hutan rakyat per tahun di Kabupaten Tana Toraja cukup besar dan dapat memasok bahan baku bagi industri perkayuan secara kontinyu jika dikelola dengan baik. Secara keseluruhan alokasi luas tebangan dan taksiran jumlah produksi Hutan Pinus Rakyat di Kabupaten Tana Toraja selama satu daur (20 tahun) yang kelompokan atas empat periode lima tahunan (Rencana Kerja Lima Tahunan), masing-masing disajikan pada Tabel 6.

Tabel 4. Rencana Alokasi Penebangan dan Target Produksi pada Tiap Kecamatan

\begin{tabular}{|c|c|c|c|c|c|c|}
\hline \multirow{3}{*}{ Kecamatan } & \multirow{3}{*}{$\begin{array}{l}\text { Luas Total } \\
\qquad(\mathrm{Ha})\end{array}$} & \multirow{3}{*}{$\begin{array}{l}\text { Luas Efektif } \\
\qquad(\mathrm{Ha})\end{array}$} & \multicolumn{4}{|c|}{ Etat } \\
\hline & & & \multirow{2}{*}{$\begin{array}{l}\text { Luas } \\
\text { (Ha/thn) }\end{array}$} & \multirow{2}{*}{$\begin{array}{l}\text { Jumlah } \\
\text { pohon } \\
\text { (btg/thn) }\end{array}$} & \multicolumn{2}{|c|}{ Volume } \\
\hline & & & & & (m³/thn) & $\left(\mathrm{m}^{3} / \mathrm{bln}\right)$ \\
\hline 1. Mengekendek & $2.702,6$ & $2.026,9$ & 101,3 & 30.491 & $17.102,1$ & $1.425,2$ \\
\hline 2. Sangalla & $1.595,0$ & $1.196,3$ & 59,8 & 17.043 & $12.384,8$ & $1.032,1$ \\
\hline 3. Buntao' Rantebua & $1.216,0$ & 912,0 & 45,6 & 13.999 & $9.284,6$ & 773,7 \\
\hline 4. Tondon Naggala & 142,6 & 106,9 & 5,3 & 1.670 & 793,6 & 66,1 \\
\hline 5. Rantetayo & $1.617,5$ & $1.213,1$ & 60,7 & 19.121 & $9.005,0$ & 750,4 \\
\hline 6. Saluputti & 321,8 & 241,4 & 12,1 & 3.243 & $1.611,3$ & 134,3 \\
\hline 7. Bittuang & 418,0 & 313,5 & 15,7 & 4.663 & $2.245,1$ & 187,1 \\
\hline 8. Rindingallo & $2.010,0$ & $1.507,5$ & 75,4 & 24.430 & $11.040,9$ & 920,1 \\
\hline 9. Sesean & 105,0 & 78,8 & 3,9 & 1.326 & 576,8 & 48,1 \\
\hline 10. Sa'dan Balusu & 169,0 & 126,8 & 6,3 & 1.935 & 936,9 & 78,1 \\
\hline Jumlah & $10.297,4$ & 7.723 & 386,2 & 117.920 & $64.981,1$ & $5.415,1$ \\
\hline
\end{tabular}

Sumber : Hasil Analisis Data Tahun 2005
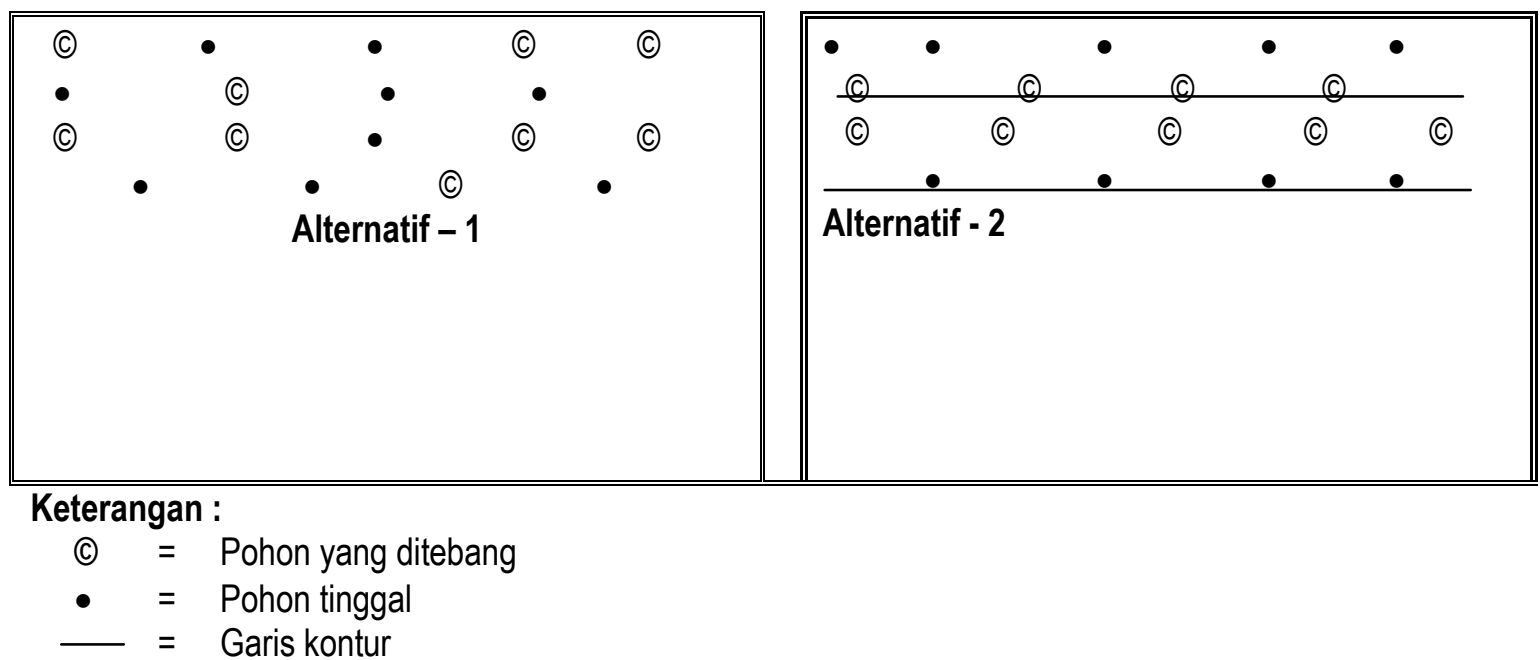

Gambar 2. Diagram Sistem (Pola) Penebangan Hutan 'Pinus' Rakyat di Kabupaten Tana Toraja 
Tabel 5. Rencana Alokasi Penebangan dan Target Produksi pada Tiap SHPR

\begin{tabular}{|c|c|c|c|c|c|c|}
\hline \multirow{3}{*}{ SPHR } & \multirow{3}{*}{$\begin{array}{l}\text { Luas Total } \\
\qquad(\mathrm{Ha})\end{array}$} & \multirow{3}{*}{$\begin{array}{l}\text { Luas Efektif } \\
\qquad(\mathrm{Ha})\end{array}$} & \multicolumn{4}{|c|}{ Etat } \\
\hline & & & \multirow{2}{*}{$\begin{array}{l}\text { Luas } \\
\text { (Ha/thn) }\end{array}$} & \multirow{2}{*}{$\begin{array}{l}\text { Jumlah Pohon } \\
\text { (btg/thn) }\end{array}$} & \multicolumn{2}{|c|}{ Volume } \\
\hline & & & & & $\left(m^{3} /\right.$ thn $)$ & $\left(m^{3} / b \mid n\right)$ \\
\hline SPHR - I & $4.297,6$ & $3.223,2$ & 161,2 & 47.534 & $29.486,9$ & $2.457,2$ \\
\hline SPHR - II & $1.358,6$ & $1.018,9$ & 50,9 & 15.669 & $10.078,2$ & 839,9 \\
\hline SPHR - III & $2.357,3$ & $1.768,0$ & 88,4 & 27.027 & $12.861,4$ & $1.071,8$ \\
\hline SPHR - IV & $2.284,0$ & $1.713,0$ & 85,7 & 27.690 & $12.554,6$ & $1.046,2$ \\
\hline Jumlah & $10.297,4$ & $7.723,0$ & 386,2 & 117.920 & $64.981,1$ & $5.415,1$ \\
\hline
\end{tabular}

Sumber : Hasil Analisis Data Tahun 2005

Tabel 6. Alokasi tebangan lima-tahunan (RKL) selama 20 tahun pada masing-masing SPHR

\begin{tabular}{crc}
\hline \multirow{2}{*}{ SPHR } & \multicolumn{2}{c}{ Alokasi tebangan per periode lima-tahunan } \\
\cline { 2 - 3 } & Ha per RKL & $\mathrm{m}^{3}$ per RKL \\
\hline SPHR - I & 805,8 & $147.434,3$ \\
SPHR - II & 254,7 & $50.391,1$ \\
SPHR - III & 442,0 & $64.307,1$ \\
SPHR - IV & 428,3 & $62.773,2$ \\
\hline Jumlah & $1.930,7$ & $324.905,6$ \\
\hline
\end{tabular}

Sumber : Hasil Analisis Data Tahun 2005

Pada Tabel 6 dapat dilihat bahwa etat luas per RKL untuk keempat SPHR adalah sebesar 1.930,7 dengan total produksi sebesar $324.905,6 \mathrm{~m}^{3}$. Penetapan etat lima-tahunan inik dimaksudkan untuk menjadi acuan dalam penyusunan rencana jangka menengah (lima-tahunan) dan sekaligus menjadi pedoman dalam melakukan penyesuaianpenyesuaian rencana atau target kegiatan pengelolaan dan pemanfaatan hutan pinus rakyat jika hal tersebut diperlukan. Melalui penyesuaianpenyesuaian tersebut maka dapat diharapkan bahwa kelestarian dan kestabilan produksi untuk jangka panjang dapat lebih terjamin.

\section{KESIMPULAN DAN REKOMENDASI}

\section{Kesimpulan}

Berdasarkan data dan informasi yang telah dipaparkan pada bagian terdahulu maka dapat dirumuskan beberapa kesimpulan pokok sebagai berikut :

1. Dari segi potensinya, tanaman pinus rakyat pada 10 kecamatan di Kabupaten Tana Toraja layak untuk diusahakan. Hutan pinus rakyat tersebut secara keseluruhan meliputi areal seluas 10.297,4 Ha. Dengan asumsi bahwa $75 \%$ dari luasan ini dapat diusahakan secara efektif maka diperoleh taksiran total potensi hutan rakyat tersebut adalah sekitar $1.299 .622,4 \mathrm{~m}^{3}$. Melalui penerapan daur 20 tahun, maka dapat ditetapkan jatah produksi tebangan sebesar $64.981,1 \mathrm{~m}^{3}$ per tahun.

2. Berdasarkan kondisi penyebaran, luas, dan kedekatan lokasinya, maka pengelolaan hutan rakyat yang terdapat pada 10 kecamatan di Kabupaten Tana Toraja dapat dikelompokkan atas empat Satuan Pengelolaan Hutan Rakyat (SPHR). Setiap SPHR ini dapat dikelola sebagai suatu Kelas Kelestarian yang secara kontinyu memasok bahan baku kayu bagi industri perkayuan yang ada di wilayah ini.

3. Sesuai dengan kondisi tegakannya (penyebaran kelas umur tegakannya), Sistem Penebangan yang dapat digunakan untuk menjamin kelestariaan hasil dari hutan rakyat ini adalah Sistem Tebang Pilih dengan Permudaan Buatan atau Sistem Tebang Jalur searah Kontur dengan Permudaan Buatan.

\section{Rekomendasi}

Berdasarkan kesimpulan di atas maka dapat dikemukakan beberapa saran atau rekomendasi sebagai berikut :

1. Pengelolaan Hutan Rakyat di Tana Toraja harus diawali dengan penataan areal dan pengaturan produksi yang diterjemahkan kedalam perencanaan jangka panjang, jangka menengah dan tahunan. Perencanaan Jangka Panjang dibuat untuk setiap Satuan Pemangkuan Hutan Rakyat, sedang 
Perencanaan Jangka Menengah dan Jangka Tahunan dibuat untuk setiap kelompok tani hutan rakyat

2. Penataan areal hutan rakyat yang dimaksudkan pada butir satu di atas harus disertai dengan revitalisasi tata batas kawasan, khususnya tata batas antara areal hutan rakyat dan kawasan hutan negara yang sama-sama ditumbuhi tanaman pinus. Revitalisasi kawasan ini hendaknya dilakukan melalui pendekatan partisipatif yang diarahkan pada upaya pengembangan kesadaran dan tangung jawab warga masyarakat dan khususnya para pemilik hutan rakyat untuk berperanserta secara berkesinambungan dalam upaya pengamanan batas kawasan hutan negara, termasuk pengamanan kawasan hutan negara tersebut dari aktivitas illegal logging.

3. Dalam rangka mendukung penerapan Sistem Tebang Pilih dengan Permudaan Buatan atau Sistem Tebang Jalur searah Kontur dengan Permudaan Buatan, maka diperlukan adanya 'Peta Kerja' untuk setiap areal tebangan yang direncanakan. Peta kerja tersebut harus memperlihatkan penyebaran pohon-pohon yang akan ditebang. Sejalan dengan itu pula diperlukan adanya pengembangan Kelompok
Tani Hutan yang beranggotakan warga masyarakat pemilik hutan pinus yang berada dalam Satuan Pengelolaan Hutan Rakyat (SPHR) yang sama.

\section{DAFTAR PUSTAKA}

Clutter, J.L., J.C. Fortson, L.V. Pienar, G.H.Brister, and R.L. Biiley, 1982. Timber Management : A Quantitative Approach.

Davis, L. S. and K. N. Johnson, 1987. Forest Management. Third Edition. McGaw-Hill Book Company. New York.

Dinas Kehutanan dan Perkebunan Kabupaten Tana Toraja, 2005. Potensi dan Penyebaran Hutan Rakyat di Kabupaten Tana Toraja.

Malamassam, D., 1998. Inventarisasi Hutan. Diktat. Volume 1. Fakultas Pertanian dan Kehutanan, Universitas Hasanuddin. Makassar.

Simon, H., 1993. Metode Inventore Hutan. Aditiya Media. Yogyakarta.

Tiro, Muh. A., 2000. Dasar-Dasar Statistika. Edisi Revisi. State University of Makassar Press. Makassar

Diterima : 27 Mei 2006

\section{Daud Malamassam}

Lab. Perencanaan dan Sistem Informasi, Jurusan Kehutanan, Universitas Hasanuddin Kampus Tamalanrea, Jl. Perintis Kemerdekaan Km. 10, Makassar 90245

Telp./Fax. 0411-585917. Indonesia 